\title{
Comparação de alguns aditivos no controle da acidose ruminal por ácidos graxos voláteis induzida em bovinos de corte
}

Natalia Sato Minami[a]", Rejane dos Santos Sousa ${ }^{[a]}$, Francisco Leonardo Costa de Oliveira ${ }^{[a]}$, Mailson Rennan Borges Dias ${ }^{[a]}$, Flavio Perna Junior ${ }^{[b]}$, Paulo Henrique Mazza Rodrigues ${ }^{[b]}$, Enrico Lippi Ortolani[a]

\footnotetext{
[a] Departamento de Clínica Médica (VCM), Faculdade de Medicina Veterinária e Zootecnia, Universidade de São Paulo (USP), São Paulo, SP, Brasil

[b] Departamento de Nutrição e Produção Animal (VNP), Faculdade de Medicina Veterinária e Zootecnia, Universidade de São Paulo (USP), São Paulo, SP, Brasil
}

*Autor correspondente

e-mail: minaminatalia@usp.br

\section{Resumo}

A acidose ruminal é a segunda principal enfermidade em bovinos confinados no Brasil. Dois tipos de acidose podem acometer os animais: a provocada por ácido láctico e a provocada por acúmulo de ácidos graxos voláteis (ARAGVs). 0 presente experimento objetivou avaliar o efeito dos mais empregados aditivos dietéticos na prevenção dessa última modalidade de acidose. Foram empregadas 24 vacas Nelore, com $400 \mathrm{~kg}$ de peso corporal, canuladas no rúmen. Por 30 dias os animais receberam uma dieta contendo $75 \%$ de feno de capim coast-cross e 25 \% de ração concentrada balanceada, oferecida diariamente na base de 2,5\% do peso vivo. As rezes foram divididas em quatro grupos idênticos, sendo que em três deles foram adicionados na dieta total, nos 14 dias antes da indução, os seguintes aditivos: monensina (M) $300 \mathrm{mg} / \mathrm{animal} / \mathrm{d}$, virginiamicina (V) $187,5 \mathrm{mg} /$ animal/dia e V + M nas mesmas doses descritas, e um grupo controle (C). A acidose foi induzida administrando-se subitamente polpa cítrica peletizada na cânula ruminal segundo o cálculo $\mathrm{Y}(\mathrm{g})=\mathrm{Peso}$ Vivo $^{0,75}$ x 54,7. Foi acompanhada a evolução do $\mathrm{pH}$ ruminal no decorrer de $24 \mathrm{~h}$ por dois métodos diferentes: pHmetro de medição contínua (DASCOR ${ }^{\circledR}$ ), aferido para ser lido a cada 5 min, e alojado no saco ventral anterior; e pH de bancada, com leituras de amostras obtidas a cada 3 horas após a indução. 0 diagnóstico definitivo de ARAGVs foi firmado quando o $\mathrm{pH}$ se situou entre 5,6 a 5,1 por tempo mínimo de 3 h. 0 uso de $\mathrm{V}$ e de $\mathrm{V}+\mathrm{M}$ preveniu o surgimento de ARAVGS em todas as fêmeas, enquanto que a M evitou apenas em $33,3 \%$ dos animais, ocorrendo a enfermidade em todos os bovinos C. A mediana do tempo em que o $\mathrm{pH}$ ruminal esteve entre 5,6 e 5,1 foi idêntico nos grupos C (240 min) e M (312 min) (P=0,93). Apenas um animal do grupo V (55min) e outro do V+M (60 min) apresentaram pH ruminal temporariamente inferior a 
5,6. $0 \mathrm{pH}$ atingiu valores mais baixos ao redor da 6⿳⺈ $\mathrm{h}$ de indução, elevando-se gradativamente até o final do experimento. A comparação do $\mathrm{pH}$ na $6^{\mathrm{a}}$ detectou maiores valores nos grupos $\mathrm{V}(5,75 \pm 0,28)$ e $\mathrm{V}+\mathrm{M}(5,94 \pm$ $0,28)$ do que no $M(5,43 \pm 0,15)$ e $C(5,48 \pm 0,10)(P=0,002)$. Os resultados supracitados permitem concluir seguramente que a virginiamicina e a sua associação com a monensina são bastante efetivas na prevenção da ARAGVs, induzida com polpa cítrica, em bovinos de corte. 